\title{
Peranan Teknologi Informasi Dalam Mengefektifkan Keputusan Pemberian Dana Corporate Social Responsibilty (CSR)
}

\author{
Elvitrianim Purba \\ AMIK STIEKOM Sumatera Utara, Rantauprapat, Indonesia \\ Jalan Haji Adam Malik No. 18 Rantauprapat, Indonesia
}

\begin{abstract}
Abstrak
Teknologi informasi yang berkembang semakin memberikan kemudahan kepada pemakainya. Salah satu kemudahan yang ditawarkannya, yaitu memberikan solusi alternatif terbaik kepada penghasil keputusan dalam hal ini pimpinan. Sehingga pimpinan dapat dengan lebih baik dan maksimal dalam memberikan suatu keputusan. Penerapan metode dalam pemrosesan keputusan yang diinginkan cukup memberikan dampak yang baik, dan mempercepat pemrosesan keputusan dengan bantuan dari teknologi informasi tersebut. Pada penelitian ini peneliti membahas efektifitas keputusanyang dihasilkan oleh pimpinan dalam hal keputusan pemberikan dana Corporate Social Responsibility (CRS). Metode yang digunakan untuk diterapkan dalam sistem pendukung keputusan yaitu WASPAS. Diharapkan hasil keputusan ini memberikan efektifitas hasil yang maksimal kepada pimpinan dalam memutuskan desa penerima dana CSR
\end{abstract}

Kata kunci: Sistem Pendukung Keputusan, Pemberian Dana, Corporate Social Responsibility, CSR

\section{Abstract}

Information technology is growing increasingly provide convenience to the wearer. One of the ease with which it is offered is to provide the best alternative solution to the decision maker, in this case, the leader. So that leaders can with better and maximum in providing a decision. Applying the method in the desired decision processing is sufficiently good, and speeds up decision processing with the help of the information technology. In this study, researchers discuss the effectiveness of decisions generated by the leadership in terms of decisions grantors Corporate Social Responsibility (CRS). The method used to be applied in decision support system is WASPAS. It is expected that the result of this decision will give maximum effect to the leader in deciding the recipient village of CSR fund

Keywords: Decision Support System, Fund Grant, Corporate Social Responsibility, CSR

\section{PENDAHULUAN}

Perkembangan dunia usaha yang semakin pesatnya menuntut perusahaan berlomba-lomba untuk meningkatkan kualitasnya. Baik dari sisi sumber daya manusia maupun dari kegiatan Corporate Social Responsibilty(CSR) merupakan strategi perusahaan dalam mendapatkan citra yang terbaik di masyarakat pada umumnya. Sebagaimana diatur dalam undang undang no 40 tahun 2007 tentang perseroan terbatas, bahwa CSR merupakan kewajiban hukum yang harus dipatuhi oleh perusahaan. Perusahaan dalam hal ini menyadari bahwa keberhasilannya dalam mencapai suatu tujuan bukan hanya dipengaruhi oleh faktor internal namun juga oleh masyarakat yang berada di sekitar perusahaan. Banyak pihak yang beranggapan bahwa CSR merupakan sumbangan dari suatu perusahaan terhadap masyarakat yang tinggal di sekitar perusahaan ataupun masyarakat yang membutuhkan. Namun disamping itu kegiatan CSR yang dilakukan perusahaan haruslah tetap sasaran dan sesuai dengan tujuannya.

Pandangan perusahaan terhadap CSR yakni merupakan suatu program yang bersifat investasi bagi perusahaan untuk pertumbuhan perusahaan dan berkelanjutan. CSR merupakan komitmen suatu perusahaan dalam mendukung terciptanya pembangunan berkelanjutan (sustainable development). Perusahaan di Indonesia berjumlah sangat banyak saat ini, namun hanya sedikit perusahaan yang memiliki kesadaran untuk mengalokasikan dana CSR. Adanya penyaluran dana CSR dari perusahaan ke masyarakat yang terdapat dilingkungan perusahaan diharapkan mendorong perkonomian masyarakat untuk lebih berkembang.

Agar penyalurannya tepat sasaran tentu perusahaan perlu melakukan penyeleksian dalam penyaluran dana CSR tersebut. Dalam penyeleksian penyaluran dana CSR membutuhkan alat bantu berupa teknologi informasi, dalam hal ini sistem pendukung keputusan. Penggunaan teknologi informasi bagi perusahaan memang tidak asing. Suatu perusahaan yang ingin bersaing secara global tentu tidak luput dari teknologi informasi. Peranan sistem informasi dalam mengefektifkan keputusan salah satunya. Adanya alat bantu tersebut membantu pimpinan dalam menghasilkan informasi yang lebih selektif dan efektif, sehingga keputusan yang dihasilkan pimpinan lebih mengarah ke objektif bukan lagi secara subjektif. Salah satu penerapan teknologi informais pada sistem pendukung keputusan yaitu penggunaan metode metode dalam penyelesaian masalah, misalnya dengan menggunakan metode ELECTRE, TOPSIS, VIKOR, CPI, MOORA[1][2][3] dan lainnya. Banyak metode yang dapat diterapkan dalam sistem pendukung keputusan. Pada penelitian ini penulis memanfaatkan teknologi sistem informasi dalam hal ini sistem pendukung keputusan untuk meningkatkan efektifitas dalam menghasilkan keputusan untuk penerima dana 
CSR. Dalam pemrosesan keputusan penulis menggunakan metode Weighted Aggregated Sum Product Assesment (WASPAS).

\section{TEORITIS}

\subsection{Teknologi Informasi}

Teknologi Informasi merupakan istilah umum yang digunakan untuk membantu manusia dalam membuat, menyimpan, mengubah, mengomunikasikan serta menyebarkan informasi. Penerapan teknologi informasi dalam mengolah data-data penting saat ini merupakan suatu hal yang sangat penting bagi pihak manajemen. Perusahaan akan sangat tertinggal jauh apabila tidak menerapkan Teknologi informasi dalam setiap proses yang dilakukannya, termasuk didalamnya untuk pengefektifan suatu keputusan.

\subsection{Corporate Social Responsibility (CSR)}

Corporate Social Responsibility (CSR) didefinisikan sebagai suatu komitmen perusahaan untuk secara berkesinambungan bertindak etis, beroperasi secara legal serta berkontribusi pada peningkatan ekonomi baik peningkatan terhadap kualitas hidup karyawan, keluarga sekaligus pada komunitas lokal dan masyarakat. CSR dapat diartikan juga sebagai suatu kerangka strategis baru yang digunakan perusahaan dalam peningkatan daya saing dan mencapai bisnis yang berkelanjutan. Corporate Social Responsibilty (CSR) menekankan kepada perusahaan dalam mengembangkan praktik bisnis yang etis dan berkesinambungan (sustainable) secara ekonomi, sosial dan lingkungan.

Perkembangan Corporate Social Responsibility dapat dilihat dari dua perspektif yang berbeda. Pertama, CSR merupakan praktik bisnis sukarela (discretionary business practice) yang dalam artian pelaksanaannya banyak berasal dari inisiatif perusahaan. Kedua, CSR bukan merupakan discretionary business practice, yang pelaksanaannya diatur oleh undang-undang.

\subsection{Sistem Pendukung Keputusan}

Keputusan merupakan kegiatan untuk memilih suatu strategi atau tindakan dalam pemecahan masalah tertentu. Tindakan dalam memilih strategi atau aksi yang diyakini manajer dapat memberikan solusi yang terbaik atas sesuatu itu disebut pengambilan keputusan. Menurut beberapa pakar menyebutkan bahwa sistem pendukung keputusan yaitu sistem yang berbasis komputer dalam hal ini sistem informasi yang mampu memberikan alternatif keputusan yang dapat membantu manajer dalam menangani permasalahan permasalahan yang ditemui dalam manajemen[4][5][6].

\subsection{Metode Weighted Aggregated Sum Product Assesment (WASPAS)}

Metode Weighted Aggregated Sum Product Assesment (WASPAS) merupakan metode gabungan yang terdiri dari metode WP dan metode SAW, metode WASPAS ini diharapkan dapat memberikan hasil yang lebih baik dalam membantu penentuan sistem pendukung keputusan[7][8].

Langkah-langkah penyelesaian masalah menggunakan metode Weighted Aggregated Sum Product Assesment (WASPAS)[8][1], yaitu:

1. Membuat Matriks Keputusan

$$
x=\left[\begin{array}{cccc}
x_{11} & x_{12} & \cdot & x_{1 n} \\
x_{21} & x_{11} & \cdot & x_{2 n} \\
\cdot & \cdot & \cdot & \cdot \\
x_{m 1} & x_{m 1} & \cdot & x_{m n}
\end{array}\right] \ldots \ldots \ldots \ldots \ldots \ldots \ldots
$$

Dimana m adalah jumlah alternatif kandidat, $n$ adalah jumlah kriteria evaluasi dan xij adalah kinerja alternatif sehubungan dengan kriteria $\mathrm{j}$.

2. Menormalisasikan matrik $\mathrm{x}$.

Kriteri keuntungan

$x_{i j}=\frac{x_{i j}}{\max _{i} x_{i j}}$

Kriteria biaya 


$$
x_{i j}=\frac{\min _{i} x_{i j}}{x_{i j}}
$$

3. Menghitung Preferensi (Qi)

$$
Q_{i}=0.5 \sum_{j=1}^{n} x_{i j} w_{j}+0.5 \prod_{j=1}^{n}\left(x_{i j}\right) w_{j}
$$

Alternatif yang terbaik merupakan alternatif yang memiliki Qi dengan nilai tertinggi.

\section{ANALISA DAN PEMBAHASAN}

Dalam penentuan penerima dana CSR menggunakan teknologi informasi, dalam hal ini menggunakan sistem pendukung keputusan yang dalam penerapannya memanfaatkan suatu metode yang bernama Weighted Aggregated Sum Product Assesment (WASPAS). Metode ini bertujuan untuk melakukan perbandingan dengan menghitung antara bobot dari setiap kriteria dengan alternatif yang ada. Tujuan pemakaian metode ini diharapkan dapat menghasilkan informasi yang efektif yang dapat membantu manajemen perusahaan dalam memutuskan penerima dana CSR tersebut.

Dalam penerapan metode WASPAS ini, membutuhkan kriteria yaitu Bermanfaat, Jangka Panjang, Jarak Dengan Wilayah Operasi, Publikasi, Mendukung Prepare Perusahaan dan Besar Dana. Selain Kriteria juga dibutuhkan Alternatif yang berupa pengusul dana CSR. Berikut merupakan tabel 1 yaitu tabel yang berisikan kriteria.

Tabel 1. Kriteria

\begin{tabular}{lcc}
\hline \multicolumn{1}{c}{ Kriteria } & Bobot & Tipe \\
\hline Bermanfaat $\left(\mathrm{C}_{1}\right)$ & $15 \%$ & Benefit \\
Jangka Panjang (Tahun) $\left(\mathrm{C}_{2}\right)$ & $20 \%$ & Benefit \\
Jarak Dengan Wilayah Operasi $(\mathrm{Km})\left(\mathrm{C}_{3}\right)$ & $25 \%$ & Cost \\
Publikasi $\left(\mathrm{C}_{4}\right)$ & $10 \%$ & Benefit \\
Mendukung Prepare Perusahaan $\left(\mathrm{C}_{5}\right)$ & $10 \%$ & Benefit \\
Besar Dana (Juta) $\left(\mathrm{C}_{6}\right)$ & $20 \%$ & Cost \\
\hline
\end{tabular}

Pada tabel 2, merupakan tabel alternatif yang merupakan tabel pengusul dana CSR.

Tabel 2. Alternatif

\begin{tabular}{c}
\hline Alternatif \\
\hline Desa A $\left(\mathrm{A}_{1}\right)$ \\
Desa B $\left(\mathrm{A}_{2}\right)$ \\
Desa C $\left(\mathrm{A}_{3}\right)$ \\
Desa D $\left(\mathrm{A}_{4}\right)$ \\
Desa E $\left(\mathrm{A}_{5}\right)$ \\
\hline
\end{tabular}

Setelah data alternatif dan kriteria tersedia maka dibutuhkan data rating kecocokan yang terlihat pada tabel 3.

Tabel 3. Rating kecocokan alternative dan kriteria

\begin{tabular}{ccccccc}
\hline Alternatif & $\mathbf{C}_{\mathbf{1}}$ & $\mathbf{C}_{\mathbf{2}}$ & $\mathbf{C}_{\mathbf{3}}$ & $\mathbf{C}_{\mathbf{4}}$ & $\mathbf{C}_{\mathbf{5}}$ & $\mathbf{C}_{\mathbf{6}}$ \\
\hline $\mathrm{A}_{1}$ & 70 & 3 & 10 & 80 & 90 & 15 \\
$\mathrm{~A}_{2}$ & 80 & 2 & 15 & 83 & 86 & 20 \\
$\mathrm{~A}_{3}$ & 76 & 3 & 9 & 79 & 89 & 14 \\
$\mathrm{~A}_{4}$ & 81 & 4 & 10 & 83 & 90 & 25 \\
$\mathrm{~A}_{5}$ & 79 & 2 & 7 & 80 & 89 & 23 \\
$\mathrm{~W}$ & 0,15 & 0,2 & 0,25 & 0,1 & 0,1 & 0,2 \\
\hline
\end{tabular}

Bobot pada setiap kriteria di definisikan sebagai W yaitu $[0,15 ; 0,2 ; 0,25 ; 0,1 ; 0,1 ; 0,2]$, berikut langkah WASPAS untuk menentukan penerima dana CSR perusahaan.

1. Langkah pertama membuat matrik keputusan. 
MEDIA INFORMATIKA BUDIDARMA, Vol 2, No 3, Juli 2018

ISSN 2614-5278 (media cetak)

ISSN 2548-8368 (media online)

Hal 69-75

$$
X=\left[\begin{array}{cccccc}
70 & 3 & 10 & 80 & 90 & 15 \\
80 & 2 & 15 & 83 & 86 & 20 \\
76 & 3 & 9 & 79 & 89 & 14 \\
81 & 4 & 10 & 83 & 90 & 25 \\
79 & 2 & 7 & 80 & 89 & 23
\end{array}\right]
$$

2. Langkah selanjutnya yaitu menghitung Matrik Ternormalisasi

$$
\begin{aligned}
& X_{11}=70 / 81=0,8642 \\
& X_{21}=80 / 81=0,9877 \\
& X_{31}=76 / 81=0,9383 \\
& X_{41}=81 / 81=1 \\
& X_{51}=79 / 81=0,9753 \\
& X_{12}=3 / 4=0,75 \\
& X_{22}=2 / 4=0,5 \\
& X_{32}=3 / 4=0,75 \\
& X_{42}=4 / 4=1 \\
& X_{52}=2 / 4=0,5 \\
& X_{13}=7 / 10=0,7 \\
& X_{23}=7 / 15=0,4667 \\
& X_{33}=7 / 9=0,7778 \\
& X_{43}=7 / 10=0,7 \\
& X_{53}=7 / 7=1 \\
& X_{14}=80 / 83=0,9639 \\
& X_{24}=83 / 83=1 \\
& X_{34}=79 / 83=0,9518 \\
& X_{44}=83 / 83=1 \\
& X_{54}=80 / 83=0,9639 \\
& X_{15}=90 / 90=1 \\
& X_{25}=86 / 90=0,9556 \\
& X_{35}=89 / 90=0,9889 \\
& X_{45}=90 / 90=1 \\
& X_{55}=89 / 90=0,9889 \\
& X_{16}=14 / 15=0,9333 \\
& X_{26}=14 / 20=0,7 \\
& X_{36}=14 / 14=1 \\
& X_{46}=14 / 25=0,56 \\
& X_{56}=14 / 23=0,6087 \\
& =70
\end{aligned}
$$

Dari hasil perhitungan di atas, dapat dilihat pada matrik berikut ini: 
MEDIA INFORMATIKA BUDIDARMA, Vol 2, No 3, Juli 2018

ISSN 2614-5278 (media cetak)

ISSN 2548-8368 (media online)

Hal 69-75

$\mathrm{X}=\left[\begin{array}{cclccr}0,8642 & 0,75 & 0,7 & 0,9639 & 1 & 0,9333 \\ 0,9877 & 0,5 & 0,4667 & 1 & 0,9556 & 0,7 \\ 0,9383 & 0,75 & 0,778 & 0,9518 & 0,9889 & 1 \\ 1 & 1 & 0,7 & 1 & 1 & 0,56 \\ 0,9753 & 0,5 & 1 & 0,9639 & 0,9889 & 0,6087\end{array}\right]$

3. Berdasarkan persamaan 4, maka di cari nilai Qi.

Untuk nilai $\mathrm{Q}_{1}$

$$
\begin{aligned}
Q_{1}= & 0,5 \sum(0,8642 * 0,15)+(0,75 * 0,2)+(0,7 * 0,25)+(0,9639 * 0,1)+(1 * 0,1)+(0,9333 * 0,2) \\
& * 0,5 \prod(0,8642)^{0,15}+(0,75)^{0,2}+(0,7)^{0,25}+(0,9639)^{0,1}+(1)^{0,1}+(0,9333)^{0,2} \\
& =0,5 \sum(0,1296+0,15+0,175+0,0964+0,1+0,1867) \\
& * 0,5 \prod(0,9783 * 0,9441 * 0,9147 * 0,9963 * 1 * 0,9863) \\
& =0,5 * 0,8377 * 0,5 * 0,8302=0,4189+0,4151=0,834
\end{aligned}
$$

Untuk nilai $\mathrm{Q}_{2}$

$$
\begin{aligned}
Q_{2} & =0,5 \sum(0,9877 * 0,15)+(0,5 * 0,2)+(0,4667 * 0,25)+(1 * 0,1)+(0,9556 * 0,1)+(0,7 * 0,2) \\
& * 0,5 \prod(0,9877)^{0,15}+(0,5)^{0,2}+(0,4667)^{0,25}+(1)^{0,1}+(0,9556)^{0,1}+(0,7)^{0,2} \\
& =0,5 \sum(0,1482+0,1+0,1167+0,1+0,0956+0,14) * 0,5 \Pi(0,9981 * 0,8706 * 0,8265 * 1 * 0,9955 * 0,9311) \\
& =0,5 * 0,7005 * 0,5 * 0,6657=0,3503+0,3329=0,6832
\end{aligned}
$$

Untuk nilai $\mathrm{Q}_{3}$

$$
\begin{aligned}
Q_{3}= & 0,5 \sum(0,9383 * 0,15)+(0,75 * 0,2)+(0,778 * 0,25)+(0,9518 * 0,1)+(0,9889 * 0,1)+(1 * 0,2) \\
& * 0,5 \prod(0,9383)^{0,15}+(0,75)^{0,2}+(0,778)^{0,25}+(0,9518)^{0,1}+(0,9889)^{0,1}+(1)^{0,2} \\
= & 0,5 \sum(0,1407+0,15+0,1945+0,0952+0,0989+0,2) \\
& * 0,5 \prod(0,9967 * 0,9441 * 0,9392 * 0,9951 * 0,9989 * 1) \\
= & 0,5 * 0,8793 * 0,5 * 0,8785=0,4397+0,4393=0,879
\end{aligned}
$$

Untuk nilai $\mathrm{Q}_{4}$

$$
\begin{aligned}
Q_{4}= & 0,5 \sum(1 * 0,15)+(1 * 0,2)+(0,7 * 0,25)+(1 * 0,1)+(1 * 0,1)+(0,56 * 0,2) \\
& * 0,5 \prod(1)^{0,15}+(1)^{0,2}+(0,7)^{0,25}+(1)^{0,1}+(1)^{0,1}+(0,56)^{0,2} \\
= & 0,5 \sum(0,15+0,2+0,175+0,1+0,1+0,112) * 0,5 \prod(1 * 1 * 0,9147 * 1 * 1 * 0,8905) \\
= & 0,5 * 0,837 * 0,5 * 0,8145=0,4185+0,4073=0,8258
\end{aligned}
$$

Untuk nilai $Q_{5}$

$$
\begin{aligned}
& Q_{5}=0,5 \sum(0,9753 * 0,15)+(0,5 * 0,2)+(1 * 0,25)+(0,9639 * 0,1)+(0,9889 * 0,1)+(0,6087 * 0,2) \\
& * 0,5 \prod(0,9753)^{0,15}+(0,5)^{0,2}+(1)^{0,25}+(0,9639)^{0,1}+(0,9889)^{0,1}+(0,6087)^{0,2} \\
&= 0,5 \sum(0,1463+0,1+0,25+0,0964+0,0989+0,1217) \\
& * 0,5 \prod(0,9963 * 0,8706 * 1 * 0,9963 * 0,998 * 0,9055) \\
&= 0,5 * 0,8133 * 0,5 * 0,7809=0,4067+0,3905=0,7972
\end{aligned}
$$

Hasil perhitungan perangkingan di atas, maka di dapat pada tabel kemudian menentukan nilai alternatif tertinggi: 
Tabel 4. Perangkingan Desa Penerima Data CSR

\begin{tabular}{ccc}
\hline Alternatif & Hasil & Rangking \\
\hline $\mathrm{A}_{3}$ & 0,879 & 1 \\
$\mathrm{~A}_{1}$ & 0,834 & 2 \\
$\mathrm{~A}_{4}$ & 0,8258 & 3 \\
$\mathrm{~A}_{5}$ & 0,7972 & 4 \\
$\mathrm{~A}_{2}$ & 0,6832 & 5 \\
\hline
\end{tabular}

Hasil dari perhitungan menggunakan metode WASPAS, bahwa $\mathrm{A}_{3}$ (Desa $\mathrm{C}$ ) merupakan alternatif terbaik untuk desa yang menerima dana CSR dari perusahaan

\section{KESIMPULAN}

Berdasarkan hasil analisa dan pembahasan disimpulkan, yaitu:

1. Penerapan teknologi informasi membantu pengambil keputusan dalam memberikan hasil keputusan yang efektif dan bersifat objektif, dengan membandingkan beberapa alternatif dari keputusan yang diambil.

2. Metode Weighted Aggregated Sum Product Assessment (WASPAS), dapat memberikan hasil yang maksimal terhadap keputusan pemberian dana CSR kepada desa yang mengajukannya.

\section{REFERENCES}

[1] E. D. Marbun, L. A. Sinaga, E. R. Simanjuntak, D. Siregar, and J. Afriany, "Penerapan Metode Weighted Aggregated Sum Product Assessment Dalam Menentukan Tepung Terbaik Untuk Memproduksi Bihun,” vol. 5, no. 1, pp. 24-28, 2018.

[2] G. Ginting, Fadlina, Mesran, A. P. U. Siahaan, and R. Rahim, “Technical Approach of TOPSIS in Decision Making,” Int. J. Recent Trends Eng. Res., vol. 3, no. 8, pp. 58-64, 2017.

[3] N. S. Tanjung, P. D. Adelina, M. K. Siahaan, E. Purba, and J. Afriany, "Sistem Pendukung Keputusan Pemilihan Guru Teladan Dengan Menggunakan Metode Composite Performance Index (CPI),” J. Ris. Komput. (JURIKOM, vol. 5, no. 1, pp. 13-18, 2018.

[4] Mesran, G. Ginting, Suginam, and R. Rahim, "Implementation of Elimination and Choice Expressing Reality ( ELECTRE ) Method in Selecting the Best Lecturer ( Case Study STMIK BUDI DARMA )," Int. J. Eng. Res. Technol. (IJERT, vol. 6, no. 2, pp. 141-144, 2017.

[5] Kusrini, Konsep dan Aplikasi Sistem Pendukung Keputusan. Yogyakarta: Andi, 2007.

[6] S. Kusumadewi, S. Hartati, A. Harjoko, and R. Wardoyo, Fuzzy Multi-Attribute Decision Making (Fuzzy MADM). Yogyakarta: Graha Ilmu, 2006.

[7] P. Simanjuntak, I. Irma, N. Kurniasih, M. Mesran, and J. Simarmata, "Penentuan Kayu Terbaik Untuk Bahan Gitar Dengan Metode Weighted Aggregated Sum Product Assessment ( WASPAS ),” J. Ris. Komput., vol. 5, no. 1, pp. 36-42, 2018.

[8] S. Barus, V. M. Sitorus, D. Napitupulu, M. Mesran, and S. Supiyandi, "Sistem Pendukung Keputusan Pengangkatan Guru Tetap Menerapkan Metode Weight Aggregated Sum Product Assesment ( WASPAS )," MEDIA Inform. BUDIDARMA, vol. 2, no. 2, pp. 10$15,2018$.

[9] Z. Turskis, E. K. Zavadskas, J. Antucheviciene, and N. Kosareva, "A Hybrid Model Based on Fuzzy AHP and Fuzzy WASPAS for Construction Site Selection Methodology,” Int. J. Comput. Commun. Control, vol. 10, no. 6, pp. 873-888, 2015.

[10] S. Chakraborty and E. K. Zavadskas, “Applications of WASPAS Method in Manufacturing Decision Making,” Informatica, vol. 25, no. 1, pp. 1-20, 2014

[11] K. Umam, V. E. Sulastri, T. Andiri, D. U. Sutiksno, and Mesran, "Perancangan Sistem Pendukung Keputusan Penentuan Prioritas Produk Unggulan Daerah Menggunakan Metode VIKOR,” J. Ris. Komput., vol. Vol 5, no. 1, pp. 43-49, 2017.

[12] D. Handoko, M. Mesran, S. D. Nasution, Y. Yuhandri, and H. Nurdiyanto, "Application Of Weight Sum Model (WSM) In Determining Special Allocation Funds Recipients," IJICS (International J. Informatics Comput. Sci., vol. 1, no. 2, pp. 31-35, 2017.

[13] S. Sugiarti, D. K. Nahulae, T. E. Panggabean, and M. Sianturi, "Sistem Pendukung Keputusan Penentuan Kebijakan Strategi Promosi Kampus Dengan Metode Weighted Aggregated Sum Product Assesment ( WASPAS ),” vol. 5, no. 2, pp. $103-108,2018$.

[14] S. W. Pasaribu, E. Rajagukguk, M. Sitanggang, R. Rahim, and L. A. Abdillah, "Implementasi Multi-Objective Optimization On The Basis Of Ratio Analysis ( MOORA ) Untuk Menentukan Kualitas Buah Mangga Terbaik,” J. Ris. Komput., vol. 5, no. 1, pp. 50-55, 2018 .

[15] J. Simarmata, Pengenalan Teknologi Komputer dan Informasi. Yogyakarta: Andi, 2006.

[16] H. Nurdiyanto and Heryanita Meilia, "SISTEM PENDUKUNG KEPUTUSAN PENENTUAN PRIORITAS PENGEMBANGAN INDUSTRI KECIL DAN MENENGAH DI LAMPUNG TENGAH MENGGUNAKAN ANALITICAL HIERARCHY PROCESS (AHP)," in Seminar Nasional Teknologi Informasi dan Multimedia 2016, 2016, no. February, pp. 1-7.

[17] P. Umami, L. A. Abdillah, and I. Z. Yadi, "Sistem pendukung keputusan pemberian beasiswa bidik misi," in Konferensi Nasional Sistem Informasi (KNSI2014), 2014.

[18] A. J. Putra, L. A. Abdillah, and H. Yudiastuti, "Penentuan sekolah dasar negeri terbaik kota Palembang dengan metode weighted sum model (WSM) dan weighted product model (WPM) menggunakan visual basic.net 2015," Sentikom, no. September, pp. 1-6, 2016.

[19] Yuhandri, "PENERAPAN DECISSION SUPPORT SYSTEM (DSS) DALAM PEMILIHAN JUDUL PKL DAN SKRIPSI STUDI KASUS UNIVERSITAS PUTRA INDONESIA YPTK PADANG,” Maj. Ilm. UPI-YPTK, vol. 1, no. 1, 2012.

[20] H. Nurdiyanto and E. Vem, "PERFORMANCE EVALUATION DECISION SUPPORT SYSTEM USING THE LECTURER ANALITYCAL HIERARCHY PROCESS (CASE STUDY: STMIK DHARMA WACANA METRO),” J. Teknol. Inf. Magister, vol. 
MEDIA INFORMATIKA BUDIDARMA, Vol 2, No 3, Juli 2018

ISSN 2614-5278 (media cetak)

ISSN 2548-8368 (media online)

Hal 69-75

1, no. 1, pp. 1-16, Feb. 2016.

[21] A. S. R. A. Binjori, H. R. B. Hutapea, M. Syahrizal, and N. Kurniasih, "Sistem Pendukung Keputusan Penentuan Handphone Bekas Terbaik Menggunakan Metode Multi-Objective Optimization on The Basis of Ratio Analysis ( MOORA )," J. Ris. Komput., vol. 5, no. 1, pp. 61-65, 2018.

[22] J. Simarmata, Rekayasan Perangkat Lunak. Bandung: Andi Offset, 2015.

[23] S. Barus, V. M. Sitorus, D. Napitupulu, M. Mesran, and S. Supiyandi, "Sistem Pendukung Keputusan Pengangkatan Guru Tetap Menerapkan Metode Weight Aggregated Sum Product Assesment (WASPAS )," MEDIA Inform. BUDIDARMA, vol. 2, no. 2, pp. 10$15,2018$.

[24] D. U. Sutiksno, S. Saptenno, M. Tangnga, and A. Shiratina, "Building The Tourist Trust Based on Integrated Marketing Communication and Tourist Experience," in The Global Advanced Research Conference on Management and Business Studies (GARCOMBS), 2015. 